\title{
Testing geodynamic models with major elements geochemistry: implications for intraplate volcanism.
}

\author{
ANTONIO MANJÓN-CABEZA CÓRDOBA ${ }^{1}$, MAXIM D. \\ BALLMER $^{21}$, CHELSEA ALLISON ${ }^{3}$ AND ESTEBAN GAZEL ${ }^{3}$ \\ ${ }^{1}$ ETH Zürich, ERDW, antonio.manjon@erdw.ethz.ch \\ ${ }^{2}$ UCL London, Earth Sciences \\ ${ }^{3}$ Cornell University, Earth and Atmospheric Sciences
}

Numerical modeling facilitates the exploration of geodynamic mechanisms that are inaccessible to direct geological sampling. However, quantitative comparison of geochemical signatures predicted by geodynamic models with real petrological analyses remains restricted. On one hand, efficient melting parameterizations are limited in terms of the information that they provide (e.g., specific major-element compositions), on the other hand, thermodynamic models are only stable across a restricted P-T-X space and not optimized for coupling with $2 \mathrm{D} / 3 \mathrm{D}$ geodynamic codes. Nonetheless, geodynamic models are only as good as the testable predictions that they provide. To further test geodynamic numerical models, we use a recently developed parameterization, which can constrain major-element geochemistry of primary magmas ( $\mathrm{wt} \%$ oxide) as a function of the P-T path, together with regional numerical models of different intraplate volcanism scenarios. We apply this method to 3D models of plume ascent and edge-drive convection (EDC) to understand the origin of volcanism in the Eastern Atlantic. We explore models with a step of lithospheric thickness (or "edge") of variable geometry, and with variable distances between an imposed plume and the edge. We predict characteristic compositional trends that depend on model parameters, such as plume temperature or distance of the plume from the continental edge, and compare them with actual melt-inclusion data from the Canary Islands and Cape Verde. We find geochemical trends ranging from alkalic - for the models without thermal anomalies or with weak plumes - to tholeiitic - for the cases with vigorous plumes. In turn, EDC alone cannot explain the volcanic fluxes observed at the Canary Islands or Cape Verde, with predicted melting rates well below $1 \mathrm{~km}^{3} / \mathrm{Myr}$. Comparison with melt inclusions points towards the importance of $\mathrm{CO}_{2}$, but a thermal anomaly (plume) is also needed. We integrate predictions of major-element compositions, melt volumes, and plume buoyancy fluxes to constrain the most likely set of relevant mantle properties for the Canaries. Our preferered model is a weak, relatively cold plume $\left(\Delta \mathrm{T}<150{ }^{\circ} \mathrm{C}\right)$, moderately rich in volatiles, that is affected by the nearby EDC pattern. 